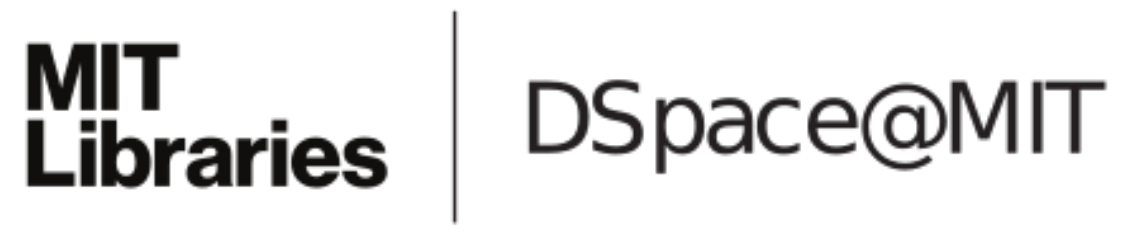

\author{
MIT Open Access Articles
}

Financial Innovation and Portfolio Risks

The MIT Faculty has made this article openly available. Please share how this access benefits you. Your story matters.

Citation: Simsek, Alp. “Financial Innovation and Portfolio Risks." American Economic Review 103, no. 3 (May 2013): 398-401. (c) 2013 the American Economic Association

As Published: http://dx.doi.org/10.1257/aer.103.3.398

Publisher: American Economic Association

Persistent URL: http://hdl.handle.net/1721.1/82669

Version: Final published version: final published article, as it appeared in a journal, conference proceedings, or other formally published context

Terms of Use: Article is made available in accordance with the publisher's policy and may be subject to US copyright law. Please refer to the publisher's site for terms of use. 


\title{
Financial Innovation and Portfolio Risks
}

\author{
By Alp SIMSEK*
}

Financial markets have recently experienced innovations that vastly increased trading opportunities. Since the 1960s, there has been a rapid expansion of new financial products such as various types of futures, options, and more exotic derivatives. By one count, there were roughly 1,200 different types of derivatives being used as of 1994 (see Duffie and Rahi 1995). There have also been improvements in information technology that dramatically reduced trading costs. For instance, the total cost of round-trip trading (buying and selling) a typical stock has declined from about 5 percent of the stock price in 1975 to less than 0.1 percent in recent years (see Turley 2012).

The traditional view in finance suggests that these innovations should facilitate risk sharing (see, for instance, Allen and Gale 1994). However, this view does not take into account that traders might naturally disagree about how to value assets. In fact, belief disagreements have recently been invoked to explain various other features of financial markets, most notably the large trading volume observed in stock markets (see Hong and Stein 2007). Belief disagreements naturally lead to speculation, which tends to increase risks in direct contrast with the traditional risk sharing view.

In recent research (Simsek 2012), I systematically analyze the channels by which financial innovation affects portfolio risks in an environment with both risk sharing needs and belief disagreements. In this paper, I illustrate the main results using a simple example. In addition to the creation of new assets, which I refer to as product innovation and which is the focus of Simsek (2012), I also consider reductions in transaction

\footnotetext{
* Department of Economics, Massachusetts Institute of Technology, E52-251C, 50 Memorial Drive, Cambridge, MA 02142 (e-mail: asimsek@mit.edu). I am grateful to Darrell Duffie for a helpful discussion.

$\dagger$ To view additional materials, and author disclosure statement(s),visit the article page at http://dx.doi.org/10.1257/aer.103.3.398.
}

costs, which I loosely refer to as process innovation. When belief disagreements are sufficiently large, both types of innovation increase traders' portfolio risks.

\section{Basic Environment}

Consider an economy with two dates, $\{0,1\}$, and a single consumption good, which will be referred to as a dollar. There are a finite number of traders denoted by $i \in I$. Each trader's endowment at date 0 is normalized to 0 (for simplicity). Trader $i$ is also endowed with $w_{i}$ dollars at date 1 , which is a random variable that captures the trader's background risks. At date 1 (and only then), traders consume. At date 0 , traders can save or borrow at a riskless rate normalized to 0 . In addition, they can also take positive or negative positions in risky assets denoted by $j \in J$. Asset $j$ is in fixed supply, normalized to 0 , and it pays $a^{j}$ dollars at date 1 .

Let $p^{j}$ denote the price of asset $j$ and $x_{i}^{j}$ denote the trader's position. To capture process innovation, suppose the trader that takes this position also pays a quadratic transaction cost given by $\frac{c^{j}}{2}\left(x_{i}^{j}\right)^{2}$, where $c^{j} \geq 0$. This cost can be viewed as part of the commissions or the bid-ask spreads that compensate the middlemen (e.g., dealers, exchange specialists) for their time and effort in making a market. ${ }^{\Gamma}$ The trader's net worth at date 1 can then be written as

$$
n_{i}=\sum_{j=1}^{J}\left(x_{i}^{j}\left(a^{j}-p^{j}\right)-\frac{1}{2} c^{j}\left(x_{i}^{j}\right)^{2}\right)+w_{i} .
$$

Trader $i$ maximizes subjective expected utility over net worth at date 1 . Her utility function takes the CARA form. I assume that asset payoffs and

\footnotetext{
${ }^{1}$ In particular, I abstract away from transaction costs that stem from information asymmetries (e.g., adverse selection).
} 
background risks are jointly normally distributed, so that the trader's optimization reduces to the usual mean-variance problem:

$$
\max _{\left\{x_{i}^{j}\right\}_{j}} E_{i}\left[n_{i}\right]-\frac{\theta_{i}}{2} \operatorname{var}_{i}\left[n_{i}\right] .
$$

Here, $E_{i}[\cdot]$ and $\operatorname{var}_{i}[\cdot]$ denote the mean and the variance of the trader's portfolio according to her belief, and $\theta_{i}$ denotes her absolute risk aversion coefficient. The equilibrium is a collection of asset prices and portfolios such that each trader $i$ chooses her portfolio optimally, and markets clear, i.e., $\sum_{i} x_{i}^{j}=0$ for each $j \in J$.

This model can be used to analyze the effect of both product and process innovation on portfolio risks. Product innovation can be captured as an expansion of the set, $J$, of traded assets. Process innovation can be captured as a reduction of transaction costs, $\left\{c^{j}\right\}_{j}$. Since traders have mean-variance preferences, portfolio risks can also be naturally measured by the variance of their net worths, $\left\{\operatorname{var}_{i}\left[n_{i}\right]\right\}_{i}$.

In Simsek (2012), I analyze product innovation for a general specification of risks and beliefs. In this paper, I consider both product and process innovation, but I restrict attention to the following simple example. Suppose there are two traders, i.e., $I=\{1,2\}$, with the same risk aversion coefficients, i.e., $\theta_{1}=\theta_{2} \equiv \theta$. The underlying uncertainty is captured by two uncorrelated and normally distributed random variables, $v_{1}, v_{2}$. Traders' background risks are perfectly correlated with one another, and they depend on a combination of the underlying random variables, that is,

$$
\begin{aligned}
& w_{1}=v \text { and } w_{2}=-v \\
& \quad \text { where } v=v_{1}+\alpha v_{2} .
\end{aligned}
$$

To keep the expressions simple, suppose also that transaction costs are the same, $c^{j} \equiv c$, for each asset $j \in J$.

As a benchmark, suppose there are no financial assets. In this case, there is no trade and traders' net worths are their background risks: $n_{1}=v$ and $n_{2}=-v$. In particular, traders' portfolios are risky because they are unable to hedge their background risks.

\section{Financial Innovation with Pure Risk Sharing}

I first use this example to illustrate the traditional risk sharing view of financial innovation. To this end, let $N\left(\mu, \sigma^{2}\right)$ denote the normal distribution with mean $\mu$ and variance $\sigma^{2}$, and suppose traders have common beliefs about both $v_{1}$ and $v_{2}$ given by $N(0,1)$. First consider product innovation. Suppose a new asset, $j=1$, is introduced to trade whose payoff is perfectly correlated with traders' endowments, $a^{1}=v$. In equilibrium, trader 1's portfolio and net worth are given by

(3) $x_{1}^{1}=\frac{-\theta\left(1+\alpha^{2}\right)}{\theta\left(1+\alpha^{2}\right)+c}, \quad n_{1}=\frac{c}{\theta\left(1+\alpha^{2}\right)+c} v$,

trader 2's portfolio and net worth are given by mirror-image expressions, and $p^{1}=0$. With common beliefs, the introduction of asset 1 enables traders to diversify their idiosyncratic risks. This leads to a reduction in portfolio risks as illustrated by the fact that $\frac{c}{\theta\left(1+\alpha^{2}\right)+c}<1$.

Next consider process innovation, that is, a reduction in transaction costs, $c$. With lower costs, traders naturally take greater risk sharing positions. This leads to a further reduction in their portfolio risks as illustrated by the fact that the scaling factor, $\frac{c}{\theta\left(1+\alpha^{2}\right)+c}$, becomes

It follows that, when traders have common beliefs, both product and process innovation facilitates risk sharing and reduces portfolio risks.

\section{Financial Innovation with Speculation and Risk Sharing}

I next consider the effect of financial innovation when traders might also have a speculative motive for trade. The key assumption is that traders have belief disagreements about some of the uncertainty in this economy (cf. equation (2)). In particular, suppose traders have common beliefs for $v_{2}$ given by the distribution $N(0,1)$. They also know that $v_{1}$ and $v_{2}$ are uncorrelated. However, they disagree about the distribution of $v_{1}$. Trader 1's prior belief for $v_{1}$ is given by $N(\varepsilon, 1)$, while trader 2's belief is given by $N(-\varepsilon, 1)$. Importantly, traders also know each other's belief, that is, they agree to 
disagree. The parameter, $\varepsilon$, captures the level of the disagreement.

In Simsek (2012), I show that, with belief disagreements, product innovation increases portfolio risks through two distinct channels. I next illustrate these channels and show that process innovation makes the second channel even stronger.

\section{A. Channel 1: Product Innovation Generates New Disagreements}

With belief disagreements, the equilibrium after the introduction of asset 1 is given by

(4) $x_{1}^{1}=\frac{-\theta\left(1+\alpha^{2}\right)+\varepsilon}{\theta\left(1+\alpha^{2}\right)+c}, \quad n_{1}=\frac{\varepsilon+c}{\theta\left(1+\alpha^{2}\right)+c} v$.

Note that traders' positions deviate from the optimal risk sharing benchmark in equation (3) in view of their disagreement, $\varepsilon$. If the disagreement is sufficiently strong, i.e., $\varepsilon>\theta\left(1+\alpha^{2}\right)$, then trader 1 is so optimistic about the payoff of the new asset that she takes a positive position, $x_{1}^{1}>0$, even though risk sharing would require her to take a negative position. As this happens, product innovation increases portfolio risks ( since $\left.\frac{\varepsilon+c}{\theta\left(1+\alpha^{2}\right)+c}>1\right)$. Intuitively, the new asset generates a new disagreement and a new source of speculation.

\section{B. Channel 2: Process and Product Innovation Amplify Speculation on Existing Disagreements}

Equation (4) also illustrates the effect of process innovation on portfolio risks. Under the same assumption, $\varepsilon>\theta\left(1+\alpha^{2}\right)$, a reduction in transaction costs, $c$, further increases portfolio risks ( since $\frac{\varepsilon+c}{\theta\left(1+\alpha^{2}\right)+c}$ is decreasing in $c$ ). When trader 1 is sufficiently optimistic, she is taking a net speculative position on the new asset. As trading costs decline, she takes a greater speculative position. Consequently, process innovation increases portfolio risks by amplifying speculation on existing disagreements.

Perhaps surprisingly, product innovation also increases portfolio risks through the same channel as process innovation. To see this, suppose $c=0$ so there is no scope for process innovation. Consider the introduction of a second asset with payoff $a^{2}=v_{2}$. This asset does not generate a new disagreement because traders agree on its payoff.

Nonetheless, Simsek (2012) shows that the introduction of this asset also increases portfolio risks in view of a subtle economic force: the hedge-more/bet-more effect. When only asset 1 is available, traders' portfolio risks are decreasing in $\alpha$, the share of $v_{2}$ in asset 1's payoff (cf. equation (4)). Intuitively, asset 1 provides traders with only an impure bet because its payoff is $v=v_{1}+\alpha v_{2}$, whereas traders only disagree about $v_{1}$. To take speculative positions, traders must hold additional risks, $v_{2}$, on which they do not disagree. Since traders are risk averse, speculation is effectively costly and therefore dampened. When asset 2 is also available, traders complement their speculative positions in asset 1 by taking the opposite positions in asset 2. This enables them to take purer bets on $v_{1}$. When traders are able to take purer bets, they also take larger bets and hold riskier portfolios.

\section{Endogenous Financial Innovation}

The analysis so far took the set of assets as exogenous. In practice, financial products are often introduced by economic agents with profit incentives. The previous literature has emphasized risk sharing as a major driving force for endogenous financial innovation (e.g., Allen and Gale 1994; Duffie and Rahi 1995; Athanasoulis and Shiller 2001). A natural question, in view of the earlier results, is whether the risk sharing motive for innovation is robust to the presence of belief disagreements.

I next address this question by endogenizing the introduction of assets in the example. Suppose the assets are designed by a profit seeking market maker who is constrained to introduce a single asset. Without loss of generality, suppose the asset has payoff

$$
a^{1}=v_{1}+\gamma v_{2},
$$

and that the market maker chooses the relative weight, $\gamma$. For simplicity, suppose there are no transaction costs, i.e., $c=0$. The market maker intermediates trade in this asset which enables it to extract some of the surplus from traders. Suppose the market maker extracts a constant fraction of the full surplus. Then, she chooses an asset design, $\gamma$, that maximizes the full 
surplus, $\sum_{i} \pi_{i}(\gamma)$, where $\pi_{i}(\gamma)$ is the trader's willingness to pay to trade the asset. In view of the mean-variance framework, $\pi_{i}(\gamma)$ is also equal to traders' certainty equivalent wealth in equilibrium with the new asset (according to her own belief) relative to her certainty equivalent wealth without the asset (cf. equation (1)).

In Simsek (2012), I characterize the optimal unconstrained asset design for a general setting. Here, I simplify the analysis further by assuming that the market maker is also constrained to choose one of two designs, $\gamma \in\{0, \alpha\}$. Note that $\gamma=\alpha$ results in an asset whose payoff is perfectly correlated with agents' portfolio risks: $a^{1}=v$. Hence, the design, $\gamma=\alpha$, can be viewed as financial innovation directed toward risk sharing. In contrast, $\gamma=0$ results in an asset whose payoff is perfectly correlated with the source of risk on which traders disagree: $a^{1}=v_{1}$. Hence, the design, $\gamma=0$, can be viewed as financial innovation directed towards speculation. I next characterize the type of financial innovation that prevails in this market.

The design $\gamma=\alpha$ results in the allocations in equation (4) with $c=0$. The willingness to pay for each trader $i \in\{1,2\}$ can be calculated as

$$
\begin{aligned}
\pi_{i}(\gamma=\alpha)= & {\left[\frac{1}{2 \theta\left(1+\alpha^{2}\right)}-\varepsilon\right] } \\
& +\frac{1}{2} \theta\left(1+\alpha^{2}\right) .
\end{aligned}
$$

Here, the second term captures each trader's gain from reduced portfolio risks, whereas the first term (in brackets) captures their perceived gain from speculation. Similarly, each trader's willingness to pay for the design $\gamma=0$ can be calculated as

$$
\pi_{i}(\gamma=0)=\left[\frac{1}{2} \frac{\varepsilon^{2}}{\theta}-\varepsilon\right]+\frac{1}{2} \theta .
$$

In this case, the gain from risk reduction is smaller since the asset is imperfectly correlated with the traders' background risks. However, the gain from speculation is greater because the asset enables the traders to take a purer bet.

Comparing equations (5) and (6) illustrates the nature of financial innovation in this example.
If the disagreement, $\varepsilon$, is sufficiently small (relative to $\theta$ ), then the market maker introduces the risk sharing design, $\gamma=\alpha$. In contrast, if $\varepsilon$ is sufficiently large, then the market maker introduces the speculative design, $\gamma=0$.

In Simsek (2012), I show that this result is general: when disagreements are large, e.g., as $\varepsilon \rightarrow \infty$, the market maker introduces assets that maximize portfolio risks among all possible choices, completely disregarding risk sharing. Intuitively, with large disagreements, speculation becomes the main motive for trade. Consequently, a profit seeking market maker introduces assets that enable the traders to speculate most precisely on their different views (which corresponds to the design, $\gamma=0$, in the example). As a by-product, the market maker also maximizes traders' portfolio risks. Taken together, these results suggest that belief disagreements can substantially change the effect of recent financial innovations on portfolio risks, as well as the driving force behind some of those innovations. The welfare implication of these results are discussed in detail in Simsek (2012).

\section{REFERENCES}

Allen, Franklin, and Douglas Gale. 1994. Financial Innovation and Risk Sharing. Cambridge, MA: MIT Press.

-Athanasoulis, Stefano G., and Robert J. Shiller. 2001. "World Income Components: Measuring and Exploiting Risk-Sharing Opportunities." American Economic Review 91 (4): 1031-54.

-Duffie, Darrell, and Rohit Rahi. 1995. "Financial Market Innovation and Security Design: An Introduction." Journal of Economic Theory 65 (1): $1-42$.

-Hong, Harrison, and Jeremy C. Stein. 2007. "Disagreement and the Stock Market." Journal of Economic Perspectives 21 (2): 109-28.

Simsek, Alp. 2012. "Speculation and Risk Sharing with New Financial Assets." http://www. economics.harvard.edu/faculty/simsek/files/ financialInnovationSpeculationStatic14.pdf.

Turley, Robert. 2012. "Informative Prices and the Cost of Capital Markets." http://www. people.fas.harvard.edu/ turley/Turley_CCM_ Nov2012.pdf. 